\title{
Occupational Stress Among Nurses Working in Intensive Care Units in Public Hospitals of Khartoum State, Sudan 2016
}

\author{
Randa Abdalla Mohamedkheir*, Zeinab Mohamed Amara, Siham Ahmed Balla, \\ Haieder Abu Ahmed Mohamed
}

Department of Community Medicine, Faculty of Medicine, University of Khartoum, Khartoum, Sudan

Email address:

randaabdalla13@hotmail.com (R. A. Mohamedkheir), zinabamara@gmail.com (Z. M. Amara), semam44@yahoo.com (S. A. Balla), dr.hayder2008@yahoo.com (H. A. A. Mohamed)

${ }^{*}$ Corresponding author

\section{To cite this article:}

Randa Abdalla Mohamedkheir, Zeinab Mohamed Amara, Siham Ahmed Balla, Haieder Abu Ahmed Mohamed. Occupational Stress Among Nurses Working in Intensive Care Units in Public Hospitals of Khartoum State, Sudan 2016. American Journal of Health Research. Vol. 4, No. 6, 2016, pp. 166-171. doi: 10.11648/j.ajhr.20160406.13

Received: September 19, 2016; Accepted: September 30, 2016; Published: October 25, 2016

\begin{abstract}
Background: Stress is frequently associated with critical care nursing. Nurses experience stressful situations in their daily working environments. Objective: To study occupational stress and stressors experienced by nurses working in intensive care units at public hospitals of Khartoum state. Methods: A cross-section study was carried at 14 public hospitals. A sample of 139 nurses was chosen by a simple random sampling technique. The nurses were interviewed by a questionnaire including Expanded Nursing Stress Likert Scale and the main factors that contribute to work-related stress. Data was managed by statistical package for social science version 20. Results: The mean score of overall occupational stress experienced by nurses was 1.88 with standard deviation of 0.50 . The analysis of stress domains revealed that nurses rated the death and dying situations as the most stressful $(\mathrm{M}=2.23 ; \mathrm{SD}=0.56)$, followed by workload $(\mathrm{M}=2.16 ; \mathrm{SD}=0.61)$ and problems with supervisors $(\mathrm{M}=2.07 ; \mathrm{SD}=0.82)$. The mean of occupational stress perceived when dealing with patients and their families was $1.92 \pm 0.62$ and stress due to uncertainty concerning treatments was $1.92 \pm 0.68$. While less occupational stress encountered in situations of problems with peers $(\mathrm{M}=1.89$; $\mathrm{SD}=0.72)$, inadequate preparations $(\mathrm{M}=1.87 ; \mathrm{SD}=0.74)$ and conflicts with physicians $(\mathrm{M}=1.73$; $\mathrm{SD}=0.68)$. The least stressful domain was discrimination $(\mathrm{M}=1.10 ; \mathrm{SD}=0.82)$. Perceived occupational stress is significantly affected by socio-demographic determinants of participants such as marital status, working experiences and the type of ICU. Conclusions: The main sources of stress experienced by critical care nurses in Khartoum state hospitals were death and dying situations and workload. Work experiences were found to be significantly associated with stress perception in critical care nurses. The findings suggest that perceived stress does vary within different types of intensive care units.
\end{abstract}

Keywords: Occupational Stress, Nurses, Intensive Care Units

\section{Introduction}

Occupational stress is defined as the harmful physical and emotional responses that occur when the requirements of the job do not match the capabilities, resources, or needs of the worker [1]. It occurs when the demands of a working environment overpower the capacities of workers to cope with. It can affect all types of workers and all professional occupations [2, 3]. Work related stress causes physical and psychological disorders [4]. It also causes change in a person's physiology that forces them to deviate from their normal functions and work environment [4].

The effects of occupational stress are considered to be devastating to both employees and employers [5]. For the organization, the results are disorganization, disruption in normal operations, and decrease in productivity [5]. For the employee, the effects of occupational stress are three folds that of the organization [5]. Studies showed that stress on 
nurses would lead to absenteeism and turnover [6]. These factors together with the burnout phenomena among nurses would affect the quality of patient care. That result in increased mortality among patients, failure to rescue and patient dissatisfaction [6].

Some studies showed that lack of job satisfaction can be a source of stress, while high satisfaction can alleviate the effects of stress [7]. Furthermore job stressors are predictive of job dissatisfaction [8]. Stress issues are considered to continue to exert influence on dissatisfaction and turnover for nurses [9-10-11].

The main stressors regarding nurses' work are workload, relationships with other clinical staff, leadership and management style, emotional needs of patients and their families, poor patient diagnosis, death and dying, shift working and lacking of reward [12].

The lack of supportive relationship or poor relationship with colleagues and supervisors are also potential sources of stress [12-13]. A study found that work overload, uncooperative patients, criticism, negligent colleagues, lack of support from supervisors, and problems with physician caused stress to hospital nurses [14].

Sources of stress in nursing include also physical labor, suffering and emotional demands of patients and families, work hours, shift work, interpersonal relationships like interand intra-professional conflict, and other pressures that are central to the nursing work $[15,16]$.

Nursing as an occupation has high level of stress [17, 18] that has a significant health problem and is a major cause of ill health at work [19-20]. Occupational stress, coping, and burnout among nurses are of universal concern to all managers and administrators in the area of health care [21]. Occupational stress encountered by critical care nursing could affect the nurse performance and reduce the capabilities to provide the appropriate care to patients in the ICU, hence the magnitude of stress need to be assessed.

Relatively few studies were conducted concerning occupational stress among nurses in Sudan. This study identified the overall stress among nurses working in ICUs and the main factors that contribute to work-related stress. It could be used to guide preventive measures and to provide methods to reduce the job stress experienced by nurses in ICUs.

\section{Methods}

This is a cross-sectional hospital-based study carried out in 14 public hospitals in Khartoum state which is one of the eighteen states of Sudan. It is the most populated $(5,274,321$ in 2008 census), and it contains the city of Khartoum, which is the national capital of Sudan. Each of the selected hospitals contains intensive care units, and provides secondary and tertiary level health services. The ICUs were general and specialized (respiratory, cardiology, neurology and paediatrics) depending on the type of hospitals.

The participants of this study were nurses working in ICUs, in public hospitals of the Khartoum state, at least working for the last six months. All nurses who satisfied these criteria and who were working during the period of the study are included. Those under training or work as a par-timer are excluded.

Sample size and sampling methods:

Study included all intensive care units in Khartoum state public hospitals

Sample size was calculated by the formula:(n) = NZ2 P (1P)/ Ne2+ Z2 P (1-P)

Where $\mathrm{n}$ is the sample size, $\mathrm{N}$ is the population size $(242$ nurses), e is the level of precision (0.05), $\mathrm{Z}$ is 1.96 at $95 \%$ confidence and $\mathrm{P}$ is the prevalence. The prevalence rates of stress among nursing staff vary across studies with researchers reporting rates of 29 to $40 \%$ [22-25].

Accordingly the sample size was 138

Sampling technique: Simple random sampling was used to select the ultimate unit (nurses). All hospitals with ICU were covered and the sample size from each hospital was determined using the probability proportionate to size (PPS)

Sample size for each hospital was calculated using the equation: $\mathrm{ni}=(\mathrm{Ni} / \mathrm{N}) * \mathrm{n}$

Where $\mathrm{Ni}$ is the total population for one hospital, ni is the sample size for one hospital, $\mathrm{n}$ is the target sample size of the study, $\mathrm{N}$ is the population size of all nurses in the hospitals

Method of data collection was individual interview of nurses using structured standard questionnaire including modified 58 items of Expanded Nursing Stress Scale (ENSS). Each item in the scale requires the respondents to rate the perception at four points ranged from1 for never stressful to 4 for extremely stressful and 0 for not applicable.

The higher the score, the more the respondent agrees that the situation was stressful. Total and sub-scales scores were derived from this instrument.

The summation of all the items in ENSS was equal to the final occupational stress score of each nurse. The scores of each subscale or domain were added up. The Cronbach's coefficient alpha of the ENSS was 0.96. This value indicated it was an instrument with high reliability to assess for the stress level of nurses [26].

Ethical clearance: In order to conduct this study this proposal was endorsed by Khartoum State Ministry of Health as well as from hospitals managers. The study participants were signed informed consent

Data Management:

Data was entered, managed and analysed using statistical package for social science version 21. Descriptive statistic and inferential statistics were produced. Minimum significance level was set at 0.05. Means, standard deviations and frequencies were presented. Prior to MANOVA analysis, Pearson correlation of ENSS subscales (domains) was carried out to identify the correlation between items at significant level of 0.01. Multiple Analysis of Variance (MANOVA)was carried to test the effect of marital status, working experiences and the types of ICU on occupational stress of nurses.

\section{Results}

Nurses' characteristics: The overall response rate was 
$100 \%$. The majority of the study participants were females, $110(79.1 \%)$ and males were $29(20.9 \%)$ [Table 1]. One hundred and six $(76.3 \%)$ of participants aged 20-29 years and $33(23.7 \%)$ aged 30 to 49 years [Table 1]. Most of the participants were single 108(77.7\%) [Table 1]. Seventy nurses $(50.1 \%)$ had 3 years or less of working duration, 57 $(41.0 \%)$ had 3 to 9 years and $12(8.6 \%)$ had more than 9 years [Table 1]. Eighty six of the participants $(61.8 \%)$ had bachelor of nursing science and 53(38.2\%) had diploma or post graduate certificate in nursing science [Table 1]. The majority of nurses had income less than 1000 Sudanese Geneh per month, 108 (77.7\%) [Table 1].

Table 1. Demographic and economic profiles of nurses working in ICUs in public hospitals of Khartoum state, Sudan 2016.

\begin{tabular}{lll}
\hline \multicolumn{2}{l}{ Demographic and economic profiles of the nurses } & $\mathbf{N}(\mathbf{\%})$ \\
\hline \multirow{2}{*}{ Gender } & Male & $29(20.9)$ \\
& Female & $110(79.1)$ \\
Age in years & $20-29$ & $106(76.3)$ \\
& $30-49$ & $33(23.7)$ \\
Marital status & Single & $108(77.7)$ \\
Educational & Married & $31(22.3)$ \\
qualification & Postgraduate certificate or diploma & $53(38.2 \%)$ \\
& Bachelor of nursing science & $86(61.8 \%)$ \\
\multirow{4}{*}{ Working duration } & Less than 3 years & $70(50.4)$ \\
& $3-$ less than 9 years & $57(41.0)$ \\
& 9 years and above & $12(8.6)$ \\
Monthly income & 1000 SDG & $108(77.7)$ \\
& More than 1000SDG & $31(22.3)$ \\
\hline
\end{tabular}

Distribution of nurses in ICUs: Seventy five nurses $(54.0 \%)$ were working in generalized ICUs, $19(14.0 \%)$ in neurology ICUs, 19 (14.0\%) in respiratory ICUs, 17 (13.0\%) in cardiology ICUs and $9(7.0 \%)$ in paediatric ICUs [Fig. 1].

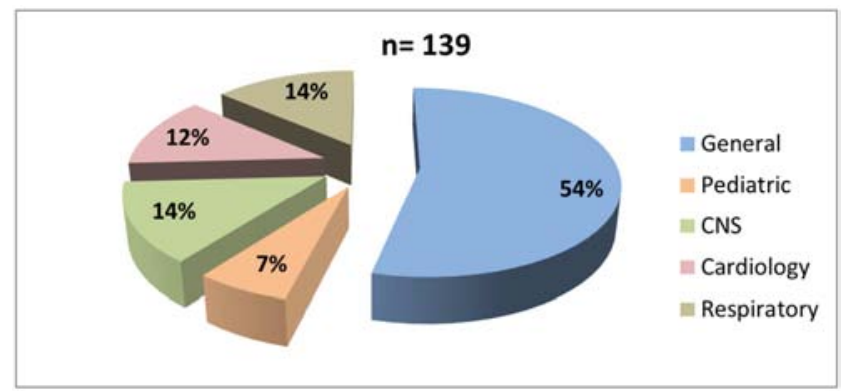

Fig. 1. Distribution of nurses by the type of intensive care units in the hospitals of Khartoum State, Sudan 2016.

Stress among nurses: The overall mean score of stress experienced by nurses was $1.88 \pm 0.50$. The mean scores of ENSS domains showed that death and dying situations had the highest stress score, $\mathrm{M}=2.23, \mathrm{SD}=0.56$, followed by workload, $\mathrm{M}=2.16, \mathrm{SD}=0.61$ and problems with supervisors, $\mathrm{M}=2.07, \mathrm{SD}=0.82$ [Table 2]. The mean stress scores of domains of patients and their families and uncertainty concerning treatments were $\mathrm{M}=1.92 ; \mathrm{SD}=0.62$ and $\mathrm{M}=1.92$; $\mathrm{SD}=0.68$ respectively [Table 2]. The discrimination domain of the scale showed a mean score of $1.10 \pm 0.82$ [Table 2].
Table 2. The mean scores of ENSS domains among nurses working in ICUs in hospitals of Khartoum state, Sudan 2016.

\begin{tabular}{|c|c|c|c|c|c|}
\hline Stress Domains & $\mathbf{N}$ & Minimum & Maximum & Mean & $\begin{array}{l}\text { Std. } \\
\text { Deviation }\end{array}$ \\
\hline $\begin{array}{l}\text { Death and } \\
\text { dying }\end{array}$ & 139 & 0.86 & 3.43 & 2.23 & 0.56 \\
\hline $\begin{array}{l}\text { Conflict with } \\
\text { physicians }\end{array}$ & 139 & 0.40 & 3.60 & 1.73 & 0.68 \\
\hline $\begin{array}{l}\text { Inadequate } \\
\text { preparation }\end{array}$ & 139 & 0.00 & 4.00 & 1.87 & 0.74 \\
\hline $\begin{array}{l}\text { Problems with } \\
\text { peers }\end{array}$ & 139 & 0.00 & 3.67 & 1.89 & 0.72 \\
\hline $\begin{array}{l}\text { Problems with } \\
\text { supervisors }\end{array}$ & 139 & 0.00 & 4.00 & 2.07 & 0.82 \\
\hline Workload & 139 & 0.40 & 3.80 & 2.16 & 0.61 \\
\hline $\begin{array}{l}\text { Uncertainty } \\
\text { concerning } \\
\text { treatment }\end{array}$ & 139 & 0.00 & 3.44 & 1.92 & 0.68 \\
\hline $\begin{array}{l}\text { Patients and } \\
\text { their families }\end{array}$ & 139 & 0.50 & 3.38 & 1.92 & 0.62 \\
\hline Discrimination & 139 & 0.00 & 3.67 & 1.10 & 0.82 \\
\hline $\begin{array}{l}\text { Total stress } \\
\text { score }\end{array}$ & 139 & 0.60 & 3.14 & 1.88 & 0.50 \\
\hline
\end{tabular}

\section{MANOVA Analysis}

Pearson Correlations between the ENSS domains was highly positive. MANOVA analysis resulted in significant relationship between the nine ENSS domains and marital status, working duration and type of the ICU. The MANOVA model excluded gender, age and educational qualifications.

\section{Stress and Marital Status}

The marital status was associated significantly to overall stress. Wilks' Lambda $=0.802, \mathrm{~F}(9 / 9)=3.538, \mathrm{P}=0.001$, partial eta squared $=0.198$ [Table 3].

Unmarried nurses experienced a higher level of stress at work in the situations of stress domains "uncertainty concerning treatment" $\mathrm{P}=0.014$, "inadequate preparation" $\mathrm{P}=0.010$ and "discrimination" 0.003 [Table 4].

\section{Stress and Working Duration}

Working duration of nurses had a significant effect on overall stress of nurses. Wilks' Lambda $=0.708$, F $(9 / 18)=$ 2.678, $\mathrm{P}=0.001$, partial eta squared $=0.158$ [Table 3].

Less than 3 years duration of work had a significant effect on nurses' stress in the situations of stress domains "death and dying" $\mathrm{P}=.021$ and "discrimination" $\mathrm{P}=.009$. Nurses who had 3-9 years duration of work were more stressed than those who had more than 9 years duration in situation of stress domains "death and dying" $\mathrm{P}=0.019$ and "dealing with patients and their families" $\mathrm{P}=0.005$ [Table 4].

\section{Stress and the Type of ICU}

The ICU type had a significant effect on the overall stress of nurses. Wilks' Lambda $=0.621$, F $(9 / 36)=1.78, \mathrm{P}=0.004$, partial eta squared $=0.112$ [Table 3].

Nurses who worked in cardiology ICU experienced more stress than those worked in CNS ICUs regarding situation of stress domains "death and dying" $\mathrm{P}=0.039$, "workload" $\mathrm{P}=0.011$ and "problem with supervisors" $\mathrm{P}=0.030$. They were also experienced significant stress more than those worked in respiratory ICU in situation of stress domains "dealing with patients and their families" $\mathrm{P}=0.011$, "workload" $\mathrm{P}=0.006$, 
"problem with peers" $\mathrm{P}=0.011$ and "uncertainty concerning treatments" $\mathrm{P}=0.004$ [Table 4].

Nurses who worked in generalized ICU experienced significant stress than those worked in paediatrics ICU regarding "death and dying" $\mathrm{P}=0.030$ and significantly stressed more than those working in respiratory ICU in situations of stress domains "inadequate preparation" $\mathrm{P}=0.030$, "problems with peers" $\mathrm{P}=0.000$, "uncertainty concerning treatments" $\mathrm{P}=0.012$, and "dealing with Patients and their families" $\mathrm{P}=0.006$ [Table 4].

Those working in paediatrics ICU experienced significant stress regarding the situation of stress domain "problem with peers" compared to nurses worked in CNS ICUs $\mathrm{P}=0.021$ and compared to those worked in respiratory ICU $\mathrm{P}=0.001$ [Table 4].

Table 3. General factors significantly associated with overall stress among nurses working in ICUs in public hospitals of Khartoum state, Sudan 2016.

\begin{tabular}{llll}
\hline Factors & F value & Partial eta squared & P value \\
\hline Marital status & 3.538 & 0.198 & 0.001 \\
Working duration & 2.678 & 0.158 & 0.001 \\
Type of ICU & 1.78 & 0.112 & 0.004 \\
\hline
\end{tabular}

Those working in paediatrics ICU experienced significant stress regarding the situation of stress domains "problem with peers" compared to nurses worked in CNS ICUs $\mathrm{P}=0.021$ and those worked in respiratory ICU $\mathrm{P}=0.001$.

Table 4. Factors significantly associated with stress domains among nurses working in ICUs in public hospitals of Khartoum state, Sudan 2016.

\begin{tabular}{|c|c|c|}
\hline Factors & Stress domains & P value \\
\hline \multirow{3}{*}{ Unmarried nurses compared to married nurses } & Uncertainty concerning treatment & 0.014 \\
\hline & Inadequate preparation & 0.010 \\
\hline & Discrimination & 0.003 \\
\hline \multirow{2}{*}{ Less than 3 years duration of work } & Death and dying & 0.021 \\
\hline & Discrimination & 0.009 \\
\hline \multirow{2}{*}{ Three -9 years duration of work compared to more the 9 years } & Death and dying & 0.019 \\
\hline & Dealing with patients and their families & 0.005 \\
\hline \multirow[t]{2}{*}{ Cardiology ICU compared to CNS ICU } & Workload & 0.006 \\
\hline & Problem with supervisors & 0.030 \\
\hline \multirow{4}{*}{ Cardiology ICU compared to Respiratory ICU } & Dealing with patients and their families & 0.011 \\
\hline & Workload & 0.006 \\
\hline & Problem with peers & 0.011 \\
\hline & Uncertainty concerning treatments & 0.004 \\
\hline Generalized ICU compared to Pediatrics ICU & Death and dying & 0.030 \\
\hline \multirow{3}{*}{ Generalized ICU compared to Respiratory ICU } & Problems with peers & 0.001 \\
\hline & Uncertainty concerning treatments & 0.012 \\
\hline & Dealing with Patients and their families & 0.006 \\
\hline Pediatrics ICU compared to CNS ICUs & Problem with peers & 0.021 \\
\hline Pediatrics ICU compared to Respiratory ICUs & Problem with peers & 0.001 \\
\hline
\end{tabular}

\section{Discussions}

The result of this study indicated that most of the nurses in ICUs were females and experienced high level of stress at their workplace. Their perception of stress differed according to the stressful situations. Often nurses are exposed to various stressors from the working environment in health systems and critical care nurses are more prone to stressful situations [24].

This study showed that "Death and dying" situations were the most prominent source of stress followed by work load and problems with supervisors. A study carried out among nurses working in Indonesian hospital showed that "Death and dying" was the most often occupational stressor, followed by "Workload" [23]. Another study was conducted in central China showed that "Death and dying", "Workload" and "Inadequate preparation" situations were the most common sources of nursing stress [24]. The most common stressors among 30 Filipino registered nurses were "Death and dying", "Conflict with physicians" and "Inadequate preparations" [25]. Also "Workload" followed by "Death and dying" were found to be the most common sources of stress among nurses working in the hospitals of New South Wales,
New Zealand and Michigan [26, 27].

Marital status of the participants in this study was significantly influence stress perception at work. Nurses who are single experience higher stress level than married nurses. Other studies showed married nurses experience high stress level than singles [28, 29].

Most of nurses in this study were at young ages and might look for their supervisors in stressful situations while married women have their burden from the several roles and multitasks at home as well at their working stations.

Nurses with less work experiences have been found to be more stressed compared to other nurses who had more work experiences. They had experienced more stress in situations of the death and dying; problems in dealing with patients and patient families, and felt discriminated. These findings of our study are consistent with a study at a university hospital in USA that less experienced nurses got less support from coworkers [30]. Other research on Japanese nurses found that nurses with less work experience were less likely to be adequately prepared and were more likely to be uncertain about treatment [31].

Gender was insignificantly affected the level of stress among nurses in ICUs. This finding is supported by a study 
of the relationship between gender of nurses and occupational stress [32].

Occupational stress was similar among all nurses in ICUs regardless their educational qualifications where several studies supported this finding [33, 34]. Some studies indicated that occupational stress was higher among less qualified nurses $[35,36]$.

There was significant association between the type of ICU and the overall stress perceived by nurses. This finding is supported by a study among Chinese nurses in Hong Kong and found that paediatrics nurses reported the highest stress levels [37]. This may be explained by different nursing tasks and working conditions at different ICUs settings giving up to exposure to different sources of stress. Other researchers found no differences in nurses' perception of stress due to type of ICUs`specialization [38, 39].

\section{Conclusion}

Unmarried nurses in ICUs were significantly having high level of occupational stress. Nurses with less than three years working experiences were significantly stressed. The types of ICU were significantly affect perception of stress of nurses. Death and dying are common stressor. Training of nurses on dealing with stressful situations prior to involvement in critical care setting is recommended.

\section{References}

[1] Wu H, Chi TS, Chen L, Wang L, Jin YP. Occupational stress among hospital nurses: cross-sectional survey. Journal of advanced nursing 2010; 66 (3): 627-34

[2] Cox T, Griffiths A, Cox S, Rial E. Work-Related Stress. Occupational health psychology 2010: 31-56. Wily-Blackwell.

[3] Nixon AE, Mazzola JJ, Bauer J, Krueger JR, Spector PE. Can work make you sick? A meta-analysis of the relationships between job stressors and physical symptoms. Work \& Stress 2011; 25 (1): 1-22.

[4] Paillé P. Perceived stressful work, citizenship behaviour and intention to leave the organization in a high turnover environment: Examining the mediating role of job satisfaction. Journal of Management Research 2011; 3 (1): 1.

[5] Kossek EE, Pichler S, Bodner T, Hammer LB. Workplace social support and work-family conflict: A meta - analysis clarifying the influence of general and work-family - specific supervisor and organizational support. Personnel psychology 2011; 64 (2): 289-313.

[6] Daouk-Öyry L, Anouze A-L, Otaki F, Dumit NY, Osman I. The JOINT model of nurse absenteeism and turnover: a systematic review. International journal of nursing studies 2014; 51 (1): 93-110.

[7] Knezevic B, Milosevic M, Golubic R, Belosevic L, Russo A, Mustajbegovic J. Work-related stress and work ability among Croatian university hospital midwives. Midwifery 2011;27 (2): $146-53$.

[8] Boyas J, Wind LH. Employment-based social capital, job stress, and employee burnout: A public child welfare employee structural model. Children and Youth Services Review 2010; 32 (3): 380-8.

[9] O'BRIEN - PALLAS L, Murphy GT, Shamian J, Li X, Hayes LJ.Impact and determinants of nurse turnover: a panCanadian study. Journal of nursing management 2010; 18 (8): 1073-86.

[10] Lu H, Barriball KL, Zhang X, While AE. Job satisfaction among hospital nurses revisited: a systematic review. International journal of nursing studies 2012;49 (8): 1017-38.

[11] Ravari A, Bazargan M, Vanaki Z, Mirzaei T. Job satisfaction among Iranian hospital - based practicing nurses: examining the influence of self-expectation, social interaction and organisational situations. Journal of Nursing Management 2012; 20 (4): 522-33.

[12] Tsai Y. Relationship between organizational culture, leadership behavior and job satisfaction. BMC health services research 2011;11 (1): 1 .

[13] Riggio R. Introduction to industrial and organizational psychology: Routledge 2015.

[14] Wu H, Chi TS, Chen L, Wang L, Jin YP. Occupational stress among hospital nurses: cross - sectional survey. Journal of advanced nursing 2010; 66 (3): 627-34.

[15] Nabirye RC, Brown KC, Pryor ER, Maples EH. Occupational stress, job satisfaction and job performance among hospital nurses in Kampala, Uganda. Journal of nursing management 2011;19 (6): 760-8.

[16] McHugh MD, Kutney-Lee A, Cimiotti JP, Sloane DM, Aiken LH. Nurses' widespread job dissatisfaction, burnout, and frustration with health benefits signal problems for patient care. Health Affairs 2011;30 (2): 202-10.

[17] Milutinović D, Golubović B, Brkić N, Prokeš B. Professional stress and health among critical care nurses in Serbia. Archives of Industrial Hygiene and Toxicology 2012; 63 (2): 171-80.

[18] Lim J, Bogossian F, Ahern K. Stress and coping in Australian nurses: a systematic review. International nursing review 2010;57 (1): 22-31.

[19] Nahrgang JD, Morgeson FP, Hofmann DA. Safety at work: a meta-analytic investigation of the link between job demands, job resources, burnout, engagement, and safety outcomes. Journal of Applied Psychology 2011; 96 (1): 71.

[20] Largo-Wight E. Cultivating healthy places and communities: evidenced-based nature contact recommendations. International journal of environmental health research. 2011; 21 (1): 41-61.

[21] Xianyu Y, Lambert VA. Investigation of the relationships among work place stressors, ways of coping, and the mental health of Chinese head nurses. Nurs Health Sci. 2006; 8: 14755. [PubMed]

[22] Lee E-H. Review of the psychometric evidence of the perceived stress scale. Asian Nursing Research 2012; 6 (4): 121-7.

[23] Fathi A, Nasae T and ThiangchanyaP. Workplace Stressors and Coping Strategies Among Public Hospital Nurses in Medan, Indonesia, The 2nd International Conference on Humanities and Social Sciences April 10th 2010 Faculty of Liberal Arts, Prince of Songkla University. 
[24] Qiao G, Li S and Hu J. Stress, coping, and psychological wellbeing among new graduate nurses in China, Home Health Care Management \& Practice 2011. 23 (6): 398-403

[25] Andal EM. A pilot study quantifying Filipino nursese perception of stress, Californian Journal of Health Promotion 2006. 4 (4): 88-95.

[26] Chang E, Bidewell J, Huntington A, Daly J, Johnson A, Wilson H, Lambert V and Lambert C. A survey of role stress, coping and health in Australian and New Zealand hospital nurses, International Journal of Nursing Studies 2007. 44 (8): 1354-1362.

[27] Hoffman A and Scott L. Role stress and career satisfaction among registered nurses by work shift patterns, The Journal of Nursing Administration 2003. 33 (6): 337-342.

[28] Milutinović D, et al. PROFESSIONAL STRESS AND HEALTH IN ICU NURSES IN SERBIA ArhHigRadaToksikol 2012; 63: 171-180

[29] Galanakis M, Stalikas A, Kallia H, Karagianni C, Karela C. Gender differences in experiencing occupational stress: the role of age, education and marital status. Stress Health 2009; 25: 397-404.

[30] Fiabane E, Giorgi I, Sguazzin C, Argentero P. Work engagement and occupational stress in nurses and other healthcare workers: the role of organisational and personal factors. Journal of clinical nursing 2013; 22 (17-18): 2614-24.

[31] Lambert, V.A., Lambert, C. E., Ito, M.. Workplace stressors, ways of coping and demographic characteristics as predictors of physical and mental health of Japanese hospital nurses. International Journal of Nursing Studies 2004. 41 (1), 85-97.
[32] Sharma A, Sharp D, Walker L and Monson J. Stress and burnout among colorectal surgeons and colorectal nurse specialists working in the National Health Service, Colorectal Dis. 2008. 10 (4): 397-406.

[33] Hajjaj K. The impact of job stress on organisational commitment and job satisfaction among nursing staff in Shifa hospital of Gaza strip, Journal of AlAzhar University (Gaza)Series of Social Sciences 2007. 9 (2): 95-118.

[34] Harrisson M, Loiselle C, Duquette A and SemenicS. Hardiness, work support and psychological distress among nursing assistants and registered nurses in Quebec, J AdvNurs 2002. 38 (6): 584-91

[35] Piko B. Work-related stress among nurses: a challenge for health care institutions, Perspectives in Public Health 1999. 119 (3): 156-162.

[36] Golubic R, Milosevic M, Knezevic B and Mustajbegovic J. Work-related stress, education and work ability among hospital nurses, Journal of Advanced Nursing 2009. 65 (10): 2056-2066.

[37] Callaghan P, Tak-Ying S and Wyatt P. Factors related to stress and coping among Chinese nurses in Hong Kong, J Adv Nurs 2000. 31 (6): 1518-27.

[38] Arafa M, Nazel M, Ibrahim N and Attia A. Predictors of psychological well-being of nurses in Alexandria, Egypt, International Journal of Nursing Practice 2003. 9 (5): 313-320

[39] Marium R. Occupational stress among female nurses in teaching hospitals at Damascus; University of Damascus Journal 2008. 24 (2): 475-510. 